IN PRESS 2021 - DEVELOPMENTAL PSYCHOLOGY

This version has not been copy edited and may not reflect the final version as published in Developmental Psychology.

Cognitive reflection and authoritarianism relate to how parents respond to children's science questions

\author{
Candice M. Mills ${ }^{1}$, Judith. H. Danovitch ${ }^{2}$, Victoria N. Mugambi ${ }^{1}$, \\ Kaitlin R. Sands ${ }^{1}$, \& Anthony J. Monroe ${ }^{1}$
}

\footnotetext{
${ }^{1}$ School of Behavioral and Brain Sciences, The University of Texas at Dallas, Richardson, TX 75080, USA

${ }^{2}$ Department of Psychological and Brain Sciences, University of Louisville, Louisville, KY 40292, USA
}

Acknowledgements. This work was supported by National Science Foundation grant DRL1551795 awarded to Candice Mills and grant DRL-1551862 awarded to Judith Danovitch. The authors thank the members of the UTD Think Lab and the UL KID Lab for their support with data collection, transcribing, and coding. Special thanks to Grace McClure Topete and Candice Pattisapu Fox for their support developing the coding scheme.

Author note. The study was not preregistered. The study materials have been uploaded to OSF: https://osf.io/sj9fc/?view only=c91d74d7a8fe4c68bf98c64fa7b9bc38. The data are available upon request.

Corresponding Author:

Candice Mills (candice.mills@utdallas.edu)

Phone: (972)-883-4475

Fax: (972)-883-2491

800 West Campbell Road, GR41

Richardson, TX 75080-3021 


\begin{abstract}
When children ask questions about science, parents use a variety of strategies to answer them, including providing accurate information, connecting to prior knowledge, or simply saying "I don't know." This study examines the factors underlying individual differences in parental explanatory characteristics. Parents $(N=148$; Mage $=38 ; 84 \%$ female, $16 \%$ male; $58 \%$ with Caucasian-American children; 67\% having completed college; $49 \%$ with household income over $\$ 75,000)$ of children ages 7 to 10 answered 8 questions about biology as if they were responding to their child. They also completed three measures of different aspects of reasoning and values: the Picture Vocabulary Test to measure verbal intelligence (Gershon et al., 2013), the Cognitive Reflection Test (CRT; Toplak et al., 2014), which measures the tendency to override intuitive but incorrect responses to engage in reflective thinking, and the Authoritarianism Scale (Feldman \& Stenner, 1997), which measures a parent's preference for encouraging obedience toward authority figures over encouraging their child's autonomy. Our findings support that different factors are associated with different explanatory characteristics. Parents high in reflective thinking tend to provide more connections to other knowledge in their explanations, while parents high in authoritarianism tend to provide fewer references to uncertainty and how to manage it. Implications for effective parent-child communication and children's scientific understanding will be discussed.
\end{abstract}

KEYWORDS: explanation, parents, uncertainty, authoritarianism, cognitive reflection, critical thinking 


\section{Cognitive reflection and authoritarianism relate to how parents respond to children's science questions}

When children ask questions, parents can answer them in different ways. For instance, when a child asks, "How do bats find food in the dark?", a parent could respond with accurate information, such as mentioning that bats use sound waves to judge how far away something is, or inaccurate information, such as saying that bats have strong eyesight. Certainly, receiving accurate information supports learning: when parents provide correct responses to their children's questions, children can integrate the new correct information into their conceptual framework ((Mills et al., in press).

Parents can also respond in ways that go beyond the question at hand and have additional implications for learning. For example, they might recognize that their child is unfamiliar with the idea that bats use sound waves to find food and connect that process to something more familiar to them (e.g., submarines use sonar to navigate) or to something they experienced (e.g., having watched bats emerge at dusk). When used appropriately, these bridges to other knowledge and experiences can encourage children's interests and enhance their learning (Callanan et al., 2017; Crowley et al., 2001; Fender \& Crowley, 2007; Valle \& Callanan, 2006).

Sometimes, though, parents encounter questions that they do not know how to answer, or they realize when trying to explain something that their understanding was less complete than they thought (Mills \& Keil, 2004; Rozenblit \& Keil, 2002). In these cases, they could handle their uncertainty in a number of ways. They could acknowledge that uncertainty, either explicitly (e.g., "I'm not sure") or by providing other means of finding a correct answer (e.g., "Let's Google it!"'). Alternatively, they could answer the question without providing any indication that the answer might be incorrect or that they are uncertain. Studies support that parents vary in how much they discuss uncertainty with their children (Canfield \& Ganea, 2014; McLoughlin et al., 
2021), and children notice some cues to uncertainty (Brosseau-Liard et al., 2014). Although it is not clear whether children prefer informants who appropriately acknowledge their uncertainty over those who do not (Tenney et al., 2011), when parents acknowledge uncertainty in discussions about evaluating evidence, children may talk more about evidence on their own (Luce et al., 2013; see also Butler, 2020). It seems quite plausible, then, that the way parents model uncertainty influences children. When parents model comfort with uncertainty and demonstrate how to handle that uncertainty, children may feel more comfortable admitting that they are unsure about something and have tools to seek further information. In contrast, when parents rarely admit uncertainty or how to handle not knowing something, children may place more value on being right than on thinking about learning as a process.

Clearly, parents vary drastically in how they respond to their children's questions, and there are links between how parents talk with their children and children's exploration and learning (Booth et al., 2020; Callanan et al., 2020; Luce et al., 2013). For instance, parent and experimenter use of mechanistic explanations when interacting with preschool-age children predicted children's independent performance on science tasks (Kurkul et al., 2021). However, we know far less about the reasons for individual differences in how parents respond to questions. This project fills this gap by examining how several factors predict individual differences in parents' responses to children's questions.

One factor that might influence parent responses to children's questions is their verbal ability. In general, people with higher verbal intelligence tend to be more successful in scholastic achievement (Roth et al., 2015) and in educational attainment (Plomin \& von Stumm, 2018). Parents with high verbal intelligence and/or who have achieved higher levels of education are 
likely to have more background knowledge that supports their ability to answer children's questions or elaborate on their responses through bridges to other knowledge and experiences.

Beyond verbal intelligence and education, other factors may relate to the depth and richness of parents' scientific explanations. Indeed, there is evidence that the tendency to override intuitive responses to questions to engage in deeper analytical thinking, measured by the Cognitive Reflection Test (CRT; Frederick, 2005), is a stronger predictor of some kinds of scientific reasoning than general intelligence or executive functioning (Toplak et al., 2011). Adults' CRT performance has been linked to how effectively they evaluate information, including scientific claims (Gervais, 2015) and fake news (Pennycook \& Rand, 2019), as well as how much they understand about science (Shtulman \& McCallum, 2014). People higher in cognitive reflection also tend to have better metacognitive skills (Fernbach et al., 2013). Although, to our knowledge, no research has examined how cognitive reflection relates to the explanations that adults generate, the above evidence suggests that parents higher in cognitive reflection may be better at taking into account their children's knowledge when providing explanations, and thus use bridges to other information more frequently.

Another factor that may influence how parents respond to children's questions is their attitude towards child rearing. Parents vary in how much they focus on encouraging children to be obedient and respect authority over encouraging them to think independently and express their ideas; parents who place more emphasis on obedience are considered more authoritarian. Parent authoritarianism has been linked with children's behavioral outcomes (Lansford et al., 2018) as well as children's reasoning skills (Reifen Tagar et al., 2014). For instance, preschoolaged children with parents high in authoritarianism trusted other adults who adhered to convention more so than children of parents low in authoritarianism, who were more flexible in 
their trust (Reifen Tagar et al., 2014). Children also ask more questions of authoritative teachers than authoritarian ones (Chin \& Osborne, 2008). Thus, adult authoritarianism seems to impact children's reasoning and learning behaviors.

Although there are many open questions regarding how parental authoritarianism affects children, one possibility is that more authoritarian parents more frequently model certainty in their responses, perhaps wanting to be seen as a clear authority figure who should not be doubted. In contrast, less authoritarian (i.e., more authoritative) parents may promote children's autonomy by demonstrating how to handle uncertainty such that children could find answers to their questions themselves in the future.

To explore how these factors relate to parent explanations, we used a new tool: the Prompted Explanation Task (PET). The PET is a brief, controlled experimental task designed to sample verbal explanations in a short period of time. Participants are prompted by a computer to verbally respond to questions while their responses are recorded. This type of approach has been used successfully with both college students (Vlach \& Noll, 2016) and parents (Mills et al., in press). Moreover, there is evidence that the characteristics of parent responses to the PET - in particular, how frequently parents provide correct responses - predicts children's verbal intelligence and biological knowledge (Mills et al., in press).

In the current paper, we build upon these findings to examine what predicts individual differences in the explanations that parents provided in the PET. We focus on three components of how parents responded to questions: the accuracy of their responses, whether they bridged to other knowledge and/or experiences, and how they handled uncertainty. After completing the PET, parents completed measures of verbal intelligence, cognitive reflection, and authoritarianism. We anticipated that greater cognitive reflection and verbal intelligence would 
relate to explanatory components that enrich explanations (i.e., greater accuracy and more bridges to other knowledge/experience), whereas greater authoritarianism would relate to explanatory characteristics that address uncertainty (i.e., fewer references to uncertainty or how to handle it).

\section{Method}

\section{Participants}

Participants were 148 parents ages 22-60 $(M=37.96, S D=6.85 ; 125$ females, 23 males $)$ who had at least one child between ages 7 and $10(M=8.92 ; S D=1.12,70$ females; 78 males $)$. Nine additional parents were excluded because they were unable to understand the directions or respond in English $(n=4)$, their responses could not be transcribed $(n=3)$, or they were not the child's primary caregiver $(n=2)$. Although race and ethnicity information was not collected for parents, $75 \%$ of parents identified their children as non-Hispanic and $12 \%$ as Hispanic. Parents also identified $58 \%$ of the children as Caucasian-American, $9.5 \%$ as Asian-American, $9.5 \%$ as African-American, and $7 \%$ as belonging to two or more groups. The remaining parents did not provide race and/or ethnicity information.

Of the 144 parents who reported their highest level of education, 8 reported completing high school, 37 reported completing some college, 58 reported completing college, and 41 reported completing a graduate degree. Education level was converted to a 1-4 scale for analyses.

Parents reported an annual household income (before taxes) ranging from "Less than $\$ 15,000$ " to "More than $\$ 175,000$," with $49 \%$ of the sample reporting a household income over \$75,000 (see Supplemental Materials for additional information).

A G*Power sensitivity analysis conducted for linear multiple regression, assuming .95 power, 4 predictors, and a sample size of 148, indicated sufficient sensitivity to detect an effect 
size of Cohen's $\mathrm{f}=0.13$. This analysis suggests that the sample was large enough to detect a relatively small effect.

\section{Materials and Procedure}

Parents sat at a table with a laptop computer in a private room and completed the study measures in the following order: the Prompted Explanation Task, Picture Vocabulary Test, and a questionnaire that included the authoritarian predisposition measure, Cognitive Reflection Test, and demographic information. Responses to additional measures were collected but are not included in this paper. The session lasted approximately 30 minutes. All measures and procedures were approved by The University of Texas at Dallas's institutional review board (IRB 14-32, "Seeking and Evaluating Explanations") and the University of Louisville institutional review board (17.0325, "Explanation and Learning”). This study was not preregistered. The study was not preregistered. The study materials have been uploaded to OSF: https://osf.io/sj9fc/?view only=c91d74d7a8fe4c68bf98c64fa7b9bc38. The data are available upon request.

\section{Prompted Explanation Task (PET)}

The experimenter instructed parents that they would be viewing 8 questions on the laptop screen, presented one at a time, and that they should respond the way they would imagine responding had their child asked the question on a typical day. The questions were inspired by other research regarding adult responses to children's questions (e.g., Vlach \& Noll, 2016) and were designed to vary in difficulty. To practice, parents responded to a sample question, “Can I have cookies for dinner every day this week?" The experimenter then reminded the parent of the instructions, started an audio recorder, and left the room. Parents responded to the following four how and four why questions about animal characteristics and behaviors: 
1. How do fish breathe underwater?

2. Why do dogs pant?

3. How do bats find their food in the dark?

4. Why do some birds fly south for the winter?

5. How do tadpoles turn into frogs?

6. Why do polar bears have white fur?

7. How do bees make honey?

8. Why are some birds' eggs white and others are different colors?

\section{NIH Toolbox Picture Vocabulary Test (PVT)}

To measure verbal intelligence, 112 of the 148 parents completed the PVT on an iPad (the others did not complete the PVT due to an error in the protocol). In this task, participants matched the meaning of an audio-recorded word to one of four pictures. Age-standardized scores were calculated by the NIH Toolbox software (Gershon et al., 2013).

\section{Authoritarian Predisposition}

Participants completed Feldman and Stenner's (1997) measure, where they selected which of two desirable qualities was more important for a child to have. For each of four pairs of items, an authoritarian value (e.g., respect for elders, obedience) was contrasted with a nonauthoritarian value (e.g., independence, self-reliance). The number of authoritarian responses was summed for a total score of 0 to 4 , with higher scores indicating a stronger authoritarian predisposition $(\alpha=.55)$.

\section{Cognitive Reflection Test (CRT)}

Participants completed the 7-item version of the CRT (Toplak et al., 2014), yielding a score of 0 to 7 correct responses ( $\alpha=.70$; see Supplemental Materials for full measure). 


\section{Coding}

\section{General}

Parent responses to the PET were transcribed and utterances were coded for the presence or absence of relevant characteristics (described below) and the length of each explanation.

\section{Content Accuracy}

Based on science reference materials, we identified the minimum amount of information that would be considered a correct response for each question. After reviewing a subset of the data that contained additional reasonable responses, we expanded our criteria for correct responses for some items. (See Supplemental Materials for coding scheme.)

For example, consider the following explanation of how bats find food in the dark: "It's through echolocation - they send sounds and pick up the vibrations from their sounds to find out where things are and that's how they fly." This answer was considered correct because it explained the mechanism bats use to locate objects (note that the inclusion of the term echolocation was not necessary to be correct).

In some cases, parent responses included inaccurate vocabulary or mechanisms. For instance, a response that fish breathe underwater "through their mouth" would be coded as having inaccurate content, as fish breathe through their gills.

Note that some parents did not provide a correct response but also did not provide inaccurate information, choosing instead to mention uncertainty without providing a guess (see below).

\section{Bridges}

Responses were coded as including bridges to other knowledge or experiences if parents referred to their child's background or common knowledge as part of their explanation. For 
example, this parent uses a bridge to the child's other knowledge (i.e., that people have different features) and to the child's experience (i.e., having a different skin color than their father) to provide reasons for variations in the color of bird eggs: "Probably the same reason why some people are different colors. Just like you and me are different colors than dad."

\section{Handling Uncertainty}

Two codes were used to label how parents handled uncertainty. First, if the parent indicated a lack of confidence in their answer (e.g., prefacing their explanation with "I think" or responding "I don't know"), then the response was coded as containing a knowledge limitation.

Second, responses were coded as referencing information search when they referred to gathering information from another source, such as the Internet, a book, and/or another person. For example, this parent suggests consulting two potential information sources to supplement and confirm their explanation:

Let's look up...let's get online or find a book that can kinda walk — that tells us how bees make honey...cause I know it has something to do with flying from each flower to flower...but I don't want to give you false information, so let's try to look it up and see. In order to establish intercoder reliability, two raters who were blind to all hypotheses independently coded 14 transcripts (i.e., 10\% of the total sample). They then discussed their codes, resolved disagreements, and updated the coding scheme. Next, the two raters both coded a different set of 31 transcripts (21\% of the sample) and divided the rest of the transcripts to code independently. Based on the coding for the 31 transcripts that were double coded, Cohen's kappa was calculated for each code. Kappa values ranged from .56 (for inaccurate information) to .94 (for information search). During this second set of coding, the two raters coded the rest of the data as well. All Kappas are reported in the Supplemental Materials. Note that because Kappas 
for providing inaccurate information were moderate, we review those findings with some caution, but the other Kappas are more robust.

\section{Results}

\section{Preliminary Analyses and Descriptive Statistics}

Preliminary analyses examined whether there were any measures that differed based on parent age. Older parents reported higher levels of education and scored higher on both the PVT and on the CRT ( $r \mathrm{~s}>.20, p \mathrm{~s}<.04$ ), consistent with prior research finding that parents who have children later tend to be more educated (Rindfuss \& St. John, 1983). Parental age did not relate to any differences in explanatory characteristics and thus will not be discussed further.

Descriptive statistics are provided in Table 1. Because the distribution of explanation lengths was positively skewed, we performed a loglinear transformation on length (see Mills et al., in press for additional information).

Scores on the authoritarianism scale ranged from 0 to $4(M=1.65, S D=1.24)$, and CRT scores ranged from 0 to $7(M=1.90, S D=1.83)$. Scores were moderately skewed $(.91)$, with only approximately $17 \%$ of participants scoring a 4 or higher. Because truncating the scale did not significantly alter the results, we follow prior research and use the full scale here. PVT scores ranged from 64 to $141(M=106.17, S D=15.63)$, and skewness and kurtosis were within the normal range.

Inspection of Table 1 suggests relations between authoritarianism, CRT scores, and characteristics of parental explanations. Note that the parent measures correlate with one another to some extent: parents who scored higher in authoritarianism tended to score lower on the PVT, and parents who scored higher on the CRT tended to score higher on the PVT and report higher levels of education. Explanation length also correlates with some aspects of parent explanations, 
and parents are more likely to provide longer explanations when they are more educated, have higher PVT scores, have higher CRT scores, and have lower authoritarianism scores.

To examine these relations further, we conducted separate multiple regression analyses for each explanatory characteristic with PVT scores and education level entered in the first step. For all regressions, preliminary analyses were conducted to ensure no violations of the assumptions of normality, linearity, and multicollinearity. Supplemental Materials include these same regression models with length as a predictor; results are very similar to what is reported here.

\section{Content Accuracy}

First, hierarchical linear regression was used to examine the contributions of the target predictors to the number of items for which parents provided a correct response (see Table 2). Note that parents provided correct responses for a little less than half of the items on average ( $M$ $=3.79$ out of 8$)$. PVT scores and parental education were entered in Block 1 yielding a significant model, $F(2,103)=19.51, p<.001$, explaining $28 \%$ of the variance. Authoritarian scores and CRT scores were entered in Block 2, yielding a significant model, $F(4,101)=14.70$, $p<.001$, and increasing the amount of variance explained to $37 \%$. In this second model, all four variables significantly predicted how often parents provided correct answers. Higher PVT scores and CRT scores related to more correct responses, and lower authoritarian scores related to more correct responses. Note that, because the correlation between education and correct responses was near zero, education appeared to be acting as a suppressor variable, rather than a meaningful predictor of correct responses (see Tzelgov \& Henik, 1991).

Second, hierarchical linear regression was used to examine the contributions of the target predictors on the number of items for which parents provided inaccurate information $(M=2.37$ 
out of 8; see Table 3). Because parents could provide responses that were not coded as correct but that also did not include inaccurate information (e.g., "I don't know"), and coding agreement was moderate for inaccurate information, we discuss these results with some caution. PVT scores and parental education were entered in Block 1 yielding a significant model, $F(2,103)=5.22, p$ $=.007$, explaining $9 \%$ of the variance. Authoritarian scores and CRT scores were entered in Block 2, yielding a significant model, $F(4,101)=3.73, p=.007$, and increasing the amount of variance explained to $13 \%$. In this second model, no variables significantly predicted how often parents provided inaccurate information, although authoritarianism trended in that direction $(p=$ .057). Thus, individual differences in verbal intelligence, authoritarianism, and cognitive reflection predict the frequency of correct responses, but not the frequency of providing inaccurate information.

\section{Bridges}

Parents provided bridges to other knowledge and experiences for approximately a quarter of the items on average $(M=2.01)$, but again, there was significant variability in how often they did so. A hierarchical linear regression for the number of items where parents provided bridges with PVT scores and parental education scores entered in Block 1 yielded a nonsignificant model, $F(2,103)=1.56, p=.22$, and explained only $3 \%$ of the variance (see Table 4$)$. Authoritarianism scores and CRT scores were entered in Block 2, yielding a significant model, $F(4,101)=5.00, p=.001$, and increasing the amount of variance explained to $17 \%$. In this second model, CRT scores significantly predicted how often parents provided bridges to other knowledge. Parents with higher scores in cognitive reflection provided bridging language more frequently.

\section{Handling Uncertainty}


The data can be examined in several ways to evaluate how parents handled uncertainty. One approach is to examine how often parents used language communicating that their answer may have gaps. Both references to knowledge limits and references to information search suggest that there is more to learn beyond the explanation the parent provided. Parents referenced knowledge limits for about a third of the items $(M=3.36)$ and information search for about a quarter of the items $(M=1.97)$. The number of items for which parents mentioned knowledge limits did not relate to PVT, CRT, or authoritarianism scores (see Table 1). In contrast, parents who more frequently referenced the possibility of searching for additional information tended to have higher PVT scores and lower authoritarianism scores (see Supplemental Materials for relevant regression model).

Given our interest in how parents handle uncertainty, another approach is to examine how often they use these techniques when they are actually uncertain versus when they are not. Because parents did not explicitly rate their certainty for each response, we do not know how they assessed the quality of their explanations. That said, parents frequently provided responses that were not coded as correct. Paired $t$-tests found that parents referred to knowledge limits more often when they answered incorrectly than when they were correct, $t(147)=5.95, p<.001$. In contrast, parents mentioned information search at similar rates when giving correct or incorrect answers, $t(147)=.87, p=.38$. These findings support that these explanatory characteristics can be used in different ways. Mentioning knowledge limits makes the most sense at times of uncertainty, while referencing information search can be useful anytime there is more left to learn.

Although these explanatory characteristics are not used interchangeably, they both communicate to children that an answer may have gaps that need to be filled. To further examine 
individual differences, then, we explored whether there were differences between parents who linguistically marked their incorrect responses by referencing knowledge limits and/or information search and those who did not. Of the 144 parents who provided at least one response that was not coded as correct, parents expressed uncertainty either by mentioning knowledge limits and/or referencing information search for $63 \%$ of the items $(S D=34 \%)$ for which they did not provide a correct response. Forty-nine participants indicated knowledge limits or referenced information search for every item for which they did not provide a correct response. At the other end of the spectrum, 14 parents never mentioned uncertainty or information search when providing a response that was not correct.

Our final exploratory analysis examined how participants who always addressed uncertainty $(N=49)$ differed from those who did not; those who did not may have mentioned it frequently, rarely, or not at all $(N=95)$. Parents who always addressed uncertainty scored higher on the PVT and lower in authoritarianism than those who did not, $t \mathrm{~s}>3.60, p \mathrm{~s}<.005$. A binary logistic regression found that both PVT and authoritarian scores predicted greater likelihood of being in group that always addressed uncertainty, both $p \mathrm{~s}<.025$ (see Supplemental Materials for additional information).

These exploratory analyses suggest an inverse relation between authoritarianism and acknowledging knowledge limits: more authoritarian parents appear less likely to admit uncertainty and/or explain how to handle not knowing the answer to a question.

\section{Discussion}

This research focused on three components of parental explanations - content accuracy, bridging techniques, and handling uncertainty - and potential predictors of how often parents use these explanatory techniques. Not surprisingly, parents with higher verbal intelligence scores 
provided correct responses to science questions more frequently. Additionally, parents with higher CRT scores provided more correct responses, potentially because their reasoning skills have helped them amass more knowledge over time that aids in answering these questions. Less expected was the finding that more authoritarian parents provided fewer correct responses than less authoritarian ones. We will return to this finding later in this discussion.

For the next component of parental explanations, bridging techniques, we found that parents with higher CRT scores provided bridging language more frequently. Although it is possible that parents responded to both the CRT and the parent explanation task in ways that reflected the experimental setting, rather than how they would respond in everyday life, it seems unlikely that task demands alone explain this finding: a desire to perform well in an experimental setting does not necessarily lead to better CRT performance (Enke et al., 2021). Instead, we speculate that parents who are more reflective (i.e., have higher CRT scores) put more effort into trying to scaffold their children's learning. Their ability to be reflective may also help them to be more aware of their child's understanding and better able to use techniques like bridging language to meet children at their level. In the long run, providing reflective answers to their children's questions may shape children's own approach to learning. Recent evidence supports that variability in school-age children's responses on a child version of the CRT meaningfully predicts their conceptual understanding in biology and math (Young \& Shtulman, 2020); additional research is needed to examine how parental reflectiveness may influence children's reflectiveness.

Although verbal intelligence did not predict how often parents used bridges to other knowledge or experience, the correlation trended in that direction, suggesting that additional research should explore the role of vocabulary and other markers of intelligence in parents' use 
of bridging techniques. For instance, there may be significant differences in how much parents provide bridging language based on their expertise in different domains, and domain-specific knowledge may be more important than general vocabulary in enabling parents to successfully use bridges to scaffold learning.

Turning to how parents handled uncertainty, both verbal intelligence and authoritarianism related to whether or not parents marked their ignorance when answering science questions. More specifically, parents with higher verbal intelligence scores and lower authoritarianism scores were more likely to mark answers that were not correct with either indications of uncertainty or references to information search. In addition, parents with higher authoritarianism scores were less likely to indicate uncertainty or model how to handle it.

Although more authoritarian parents were less likely to indicate uncertainty, additional research is needed to understand this finding. We suspect that parents who embrace authoritarian values tend to focus on conveying that they are authority figures when answering their children's questions, and admitting uncertainty may be seen as weakening perceptions of authority. In contrast, parents who reject authoritarian values in favor of more authoritative ones are likely more interested in promoting activities that can lead to greater autonomy, such as what to do when faced with a challenging question (see Ronfard et al., 2018 for a similar argument). Authoritarian parents provided fewer correct responses in this study, but because we did not measure parents' confidence in their answers, it is impossible to determine whether authoritarian parents were reluctant to model uncertainty or simply did not feel uncertain because they did not know that their response was incorrect. It is also possible that authoritarian parents tend to be more confident in their knowledge than less authoritarian ones, leading them to use language differently. Future research should examine whether authoritarianism relates to parents' 
perceptions of their own knowledge, their beliefs regarding how to talk with children about uncertainty, and/or other factors.

In general, the correlational nature of our data precludes causal claims about the relations between parental characteristics and explanations. Indeed, scores on the PVT, CRT, and authoritarianism scales may be tapping into different aspects of a larger construct that drives how parents approach providing explanations. Perhaps parents vary in how much they value and feel responsible for fostering scientific thinking in their children, and authoritarianism and cognitive reflection relate to this broader value. Still, our study suggests that cognitive reflection and authoritarianism make unique contributions to understanding individual differences in parent explanations.

Future research is needed to see if these connections hold outside of a mostly collegeeducated, American sample. For instance, variability in authoritarian views both within and across cultures (Park \& Lau, 2016) may have implications for how parents interact with their children and how these interactions influence children's learning. Future research should also explore how parents discuss uncertainty in direct conversation with their children. Although our laboratory-based task found that variability in parent explanations related to their other characteristics utilizing a relatively large sample for parent explanation research, it will be valuable to examine how parents manage uncertainty over time, over development, and in different contexts, and how those experiences relate to child outcomes. More broadly, in developing models of parent-child interaction, future research should consider not only what parents are saying to their children but why they might be saying it.

In sum, our findings support that multiple factors relate to the nature and content of parent explanations. In some cases, explanations relate to reasoning skills: parents who exhibit 
more reflective thinking may have a better sense of how to scaffold children's scientific understanding. In other cases, explanations are linked to values: parents who value children's autonomy over obedience to authority more clearly model how to manage uncertainty. Given that explanations play a powerful role in children's learning, we must be mindful that how parents respond to children's questions is not motivated solely by what children want to know, but also by what parents choose to convey. 


\section{References}

Booth, A. E., Shavlik, M., \& Haden, C. A. (2020). Parents' causal talk: Links to children's causal stance and emerging scientific literacy. Developmental Psychology, 56(11), 20552064. https://doi.org/10.1037/dev0001108

Brosseau-Liard, P., Cassels, T., \& Birch, S. (2014). You seem certain but you were wrong before: Developmental change in preschoolers' relative trust in Accurate versus confident speakers. PLoS ONE, 9(9), 1-6. https://doi.org/10.1371/journal.pone.0108308

Butler, L. P. (2020). The Empirical Child? A Framework for Investigating the Development of Scientific Habits of Mind. Child Development Perspectives, 14(1), 34-40. https://doi.org/10.1111/cdep.12354

Callanan, M. A., Castañeda, C. L., Luce, M. R., \& Martin, J. L. (2017). Family science talk in museums: Predicting children's engagement from variations in talk and activity. Child Development, 88(5), 1492-1504. https://doi.org/10.1111/cdev.12886

Callanan, M. A., Legare, C. H., Sobel, D. M., Jaeger, G. J., Letourneau, S., McHugh, S. R., Willard, A., Brinkman, A., Finiasz, Z., Rubio, E., Barnett, A., Gose, R., Martin, J. L., Meisner, R., \& Watson, J. (2020). Exploration, explanation, and parent-child interaction in museums. Monographs of the Society for Research in Child Development, 85(1), 7-137. https://doi.org/10.1111/mono.12412

Canfield, C. F., \& Ganea, P. A. (2014). "You could call It magic": What parents and siblings tell preschoolers about unobservable entities. Journal of Cognition and Development, 15(2), 269-286. https://doi.org/10.1080/15248372.2013.777841

Crowley, K., Callanan, M. A., Jipson, J. L., Galco, J., Topping, K., \& Shrager, J. (2001). Shared scientific thinking in everyday parent-child activity. Science Education, 85(6), 712-732. 
https://doi.org/10.1002/sce.1035

Enke, B., Gneezy, U., Hall, B., Martin, D. C., Nelidov, V., Offerman, T., \& van de Ven, J. (2021). Cognitive biases: Mistakes or missing stakes? https://www.nber.org/papers/w28650

Feldman, S., \& Stenner, K. (1997). Perceived threat and authoritarianism. Political Psychology, 18(4), 741-770. https://doi.org/10.1111/0162-895X.00077

Fender, J. G., \& Crowley, K. (2007). How parent explanation changes what children learn from everyday scientific thinking. Journal of Applied Developmental Psychology, 28(3), 189210. https://doi.org/10.1016/j.appdev.2007.02.007

Fernbach, P. M., Sloman, S. A., Louis, R. St., \& Shube, J. N. (2013). Explanation fiends and foes: How mechanistic detail determines understanding and preference. Journal of Consumer Research, 39(5), 1115-1131. https://doi.org/10.1086/667782

Frederick, S. (2005). Cognitive reflection and decision making. Journal of Economic Perspectives, 19(4), 25-42. https://doi.org/10.1257/089533005775196732

Gershon, R. C., Slotkin, J., Manly, J. J., Blitz, D. L., Beaumont, J. L., Schnipke, D., WallnerAllen, K., Golinkoff, R. M., Gleason, J. B., Hirsh-Pasek, K., Adams, M. J., \& Weintraub, S. (2013). NIH toolbox cognition battery (CB): Measuring language (vocabulary comprehension and reading decoding). Monographs of the Society for Research in Child Development, 78(4), 49-69. https://doi.org/10.1111/mono.12034

Gervais, W. M. (2015). Override the controversy: Analytic thinking predicts endorsement of evolution. Cognition, 142, 312-321. https://doi.org/10.1016/j.cognition.2015.05.011

Kurkul, K. E., Castine, E., Leech, K., \& Corriveau, K. H. (2021). How does a switch work? The relation between adult mechanistic language and children's learning. Journal of Applied Developmental Psychology, 72, 101221. https://doi.org/10.1016/j.appdev.2020.101221 
Lansford, J. E., Godwin, J., Bornstein, M. H., Chang, L., Deater-Deckard, K., Di Giunta, L., Dodge, K. A., Malone, P. S., Oburu, P., Pastorelli, C., Skinner, A. T., Sorbring, E., Steinberg, L., Tapanya, S., Uribe Tirado, L. M., Alampay, L. P., Al-Hassan, S. M., \& Bacchini, D. (2018). Parenting, culture, and the development of externalizing behaviors from age 7 to 14 in nine countries. Development and Psychopathology, 30(5), 1937-1958. https://doi.org/10.1017/S0954579418000925

Luce, M. R., Callanan, M. A., \& Smilovic, S. (2013). Links between parents' epistemological stance and children's evidence talk. Developmental Psychology, 49(3), 454-461. https://doi.org/10.1037/a0031249

McLoughlin, N., Jacob, C., Samrow, P., \& Corriveau, K. H. (2021). Beliefs about unobservable scientific and religious entites are transmitted via subtle linguistic cues in parental testimony. Journal of Cognition and Development.

Mills, C. M., \& Danovitch, J. H. (2021). Prompted explanation task (PET). OSF. https://osf.io/sj9fc/?view_only=c91d74d7a8fe4c68bf98c64fa7b9bc38

Mills, C. M., Danovitch, J. H., Mugambi, V. N., Sands, K. R., \& Fox, C. P. (in press). "Why do dogs pant?": Characteristics of parental explanations about science predict children's knowledge. Child Development.

Mills, C. M., \& Keil, F. C. (2004). Knowing the limits of one's understanding: The development of an awareness of an illusion of explanatory depth. Journal of Experimental Child Psychology, 87(1). https://doi.org/10.1016/j.jecp.2003.09.003

Park, H., \& Lau, A. S. (2016). Socioeconomic status and parenting priorities: Child independence and obedience around the world. Journal of Marriage and Family, 78(1), 4359. https://doi.org/10.1111/jomf.12247 
Pennycook, G., \& Rand, D. G. (2019). Lazy, not biased: Susceptibility to partisan fake news is better explained by lack of reasoning than by motivated reasoning. Cognition, 188(September 2017), 39-50. https://doi.org/10.1016/j.cognition.2018.06.011

Plomin, R., \& von Stumm, S. (2018). The new genetics of intelligence. Nature Review Genetics, 19(3), 148-159. https://doi.org/10.1038/nrg.2017.104.

Reifen Tagar, M., Federico, C. M., Lyons, K. E., Ludeke, S., \& Koenig, M. A. (2014). Heralding the Authoritarian? Orientation Toward Authority in Early Childhood. Psychological Science, 25(4), 883-892. https://doi.org/10.1177/0956797613516470

Rindfuss, R. R., \& St. John, C. (1983). Social determinants of age at first birth. Journal of Marriage and the Family, 45(3), 553-565. https://doi.org/https://doiorg.libproxy.utdallas.edu/10.2307/351660

Ronfard, S., Zambrana, I. M., Hermansen, T. K., \& Kelemen, D. (2018). Question-asking in childhood: A review of the literature and a framework for understanding its development. Developmental Review, 49, 101-120. https://doi.org/10.1016/j.dr.2018.05.002

Roth, B., Becker, N., Romeyke, S., Schäfer, S., Domnick, F., \& Spinath, F. M. (2015).

Intelligence and school grades: A meta-analysis. Intelligence, 53, 118-137. https://doi.org/10.1016/j.intell.2015.09.002

Rozenblit, L., \& Keil, F. C. (2002). The misunderstood limits of folk science: an illusion of explanatory depth. Cognitive Science, 26, 521-562. https://doi.org/10.1207/s15516709 $\operatorname{cog} 2605$

Shtulman, A., \& McCallum, K. (2014). Cognitive reflection predicts science understanding. Proceedings of the Annual Meeting of the Cognitive Science Society, 276-281.

Tenney, E. R., Small, J. E., Kondrad, R. L., Jaswal, V. K., \& Spellman, B. A. (2011). Accuracy, 
Confidence, and Calibration: How Young Children and Adults Assess Credibility. Developmental Psychology, 47(4), 1065-1077. https://doi.org/10.1037/a0023273

Toplak, M. E., West, R. F., \& Stanovich, K. E. (2014). Assessing miserly information processing : An expansion of the Cognitive Reflection Test. Thinking and Reasoning, 20(2), 147-168. https://doi.org/10.1111/ejh.12182

Tzelgov, J., \& Henik, A. (1991). Suppression situations in psychological research: Definitions, implications, and applications. Psychological Bulletin, 109(3), 524-536.

https://doi.org/https://doi.org/10.1037/0033-2909.109.3.524

Valle, A., \& Callanan, M. A. (2006). Similarity comparisons and relational analogies in parentchild conversations about science topics. Merrill-Palmer Quarterly, 52(1), 96-124. https://doi.org/10.1353/mpq.2006.0009

Vlach, H. A., \& Noll, N. (2016). Talking to children about science is harder than we think: characteristics and metacognitive judgments of explanations provided to children and adults. Metacognition and Learning, 11(3), 317-338. https://doi.org/10.1007/s11409-0169153-y

Young, A. G., \& Shtulman, A. (2020). Children's cognitive reflection predicts conceptual understanding in science and mathematics. Psychological Science, 31(11), 1396-1408. https://doi.org/10.1177/0956797620954449 
Table 1

Correlations between explanatory characteristics, authoritarianism, CRT, PVT, and education $(N=148$ unless otherwise noted $)$

\begin{tabular}{|c|c|c|c|c|c|c|c|c|c|c|c|}
\hline & $M$ & $S D$ & 1 & 2 & 3 & 4 & 5 & 6 & 7 & 8 & 9 \\
\hline $\begin{array}{l}\text { 1.Authoritarianism } \\
(\mathrm{N}=142)\end{array}$ & 1.65 & 1.24 & - & & & & & & & & \\
\hline 2.CRT & 1.90 & 1.83 & -.14 & - & & & & & & & \\
\hline 3.PVT $(\mathrm{N}=112)$ & 106.17 & 15.63 & $-.45 * *$ & $.39 * *$ & - & & & & & & \\
\hline $\begin{array}{l}\text { 4.Education }(\mathrm{N}= \\
\text { 144) }\end{array}$ & 2.92 & 0.87 & -.12 & $.38 * *$ & $.31 * *$ & - & & & & & \\
\hline $\begin{array}{l}\text { 5.Explanation } \\
\text { length }\end{array}$ & 1.50 & 0.34 & $-.25 * *$ & $.44 * *$ & $.48 * *$ & $.30 * *$ & - & & & & \\
\hline 6.Correct response & 3.79 & 2.02 & $-.34 * *$ & $.34 * *$ & $.54 * *$ & .05 & $.53 * *$ & - & & & \\
\hline 7.Inaccurate info & 2.37 & 1.49 & $.30 * *$ & -.14 & $-.28 * *$ & .01 & -.13 & $-.44 * *$ & - & & \\
\hline 8.Bridging & 2.01 & 1.84 & -.04 & $.38 * *$ & .18 & .13 & $.59 * *$ & $.31 * *$ & .09 & - & \\
\hline $\begin{array}{l}\text { 9.Knowledge } \\
\text { limits }\end{array}$ & 3.36 & 2.04 & -.16 & .11 & .11 & .10 & $.20 *$ & .07 & -.12 & $-.19 *$ & - \\
\hline 10.Info search & 1.97 & 1.93 & $-.28 * *$ & .08 & $.25 * *$ & .12 & $.27 * *$ & .05 & $-.35 * *$ & -.09 & $.51 * *$ \\
\hline
\end{tabular}

Note. Sample sizes vary depending on the measure as noted in the table. Explanation length was loglinearly transformed. ${ }^{*} p<.05, * * p<.01$ 
Table 2

Hierarchical Regression Results Predicting Correct Responses

\begin{tabular}{lcccccc}
\hline & \multicolumn{3}{c}{ Block 1 } & \multicolumn{3}{c}{ Block 2 } \\
\cline { 2 - 7 } Predictors & $B$ & $S E$ & $\beta$ & $B$ & $S E$ & $\beta$ \\
\hline PVT & $.07^{* *}$ & .01 & .55 & $.05^{* *}$ & .01 & .37 \\
Education & -.28 & .19 & -.13 & $-.46^{*}$ & .19 & -.21 \\
Authoritarianism & & & & $-.33^{*}$ & .14 & -.21 \\
CRT & & & $.31^{* *}$ & .10 & .28 \\
$\mathrm{R}^{2}$ & .28 & & & .37 & $.09^{*}$ \\
$\Delta \mathrm{R}^{2}$ & & & & & \\
\hline
\end{tabular}

${ }^{*} p<.05$ and $* * p<.01$ 
Table 3

Hierarchical Regression Results Predicting Inaccurate Information

\begin{tabular}{lcccccc}
\hline & \multicolumn{3}{c}{ Block 1 } & \multicolumn{3}{c}{ Block 2 } \\
\cline { 2 - 7 } Predictors & $B$ & $S E$ & $\beta$ & $B$ & $S E$ & $\beta$ \\
\hline PVT & $-.03^{* *}$ & .01 & -.31 & -.02 & .01 & -.20 \\
Education & .24 & .16 & .14 & .28 & .17 & .17 \\
Authoritarianism & & & & .24 & .13 & .20 \\
CRT & & & -.07 & .09 & -.08 \\
$\mathrm{R}^{2}$ & & .09 & & .13 & \\
$\Delta \mathrm{R}^{2}$ & & & & .04 & \\
\hline
\end{tabular}

${ }^{*} p<.05$ and $* * p<.01$ 
Table 4

Hierarchical Regression Results Predicting Bridges

\begin{tabular}{lcccccc}
\hline & \multicolumn{3}{c}{ Block 1 } & & Block 2 & \\
\cline { 2 - 7 } Predictors & $B$ & $S E$ & $\beta$ & $B$ & $S E$ & $\beta$ \\
\hline PVT & .02 & .01 & .13 & .00 & .01 & -.02 \\
Education & .16 & .21 & .07 & -.10 & .21 & -.05 \\
Authoritarianism & & & & -.13 & .16 & -.09 \\
CRT & & .03 & & $.42^{* *}$ & .11 & .41 \\
$\mathrm{R}^{2}$ & & & & .17 & \\
$\Delta \mathrm{R}^{2}$ & & & & $.14 * *$ & \\
\hline
\end{tabular}

$* p<.05$ and $* * p<.01$ 